\title{
Localization of the peptidylglycine $\alpha$-amidating monooxygenase gene (Pam) introduces a region of homology between human Chromosome $5 q$ and mouse Chromosome 1
}

\author{
A.C. Lossie, ${ }^{1}$ B.A. Eipper, ${ }^{2}$ T.A. Hand, ${ }^{2}$ S.A. Camper ${ }^{1}$ \\ ${ }^{1}$ Department of Human Genetics, The University of Michigan Medical School, Ann Arbor, Michigan 48109-0618, USA \\ ${ }^{2}$ Department of Neuroscience, The Johns Hopkins University School of Medicine, Baltimore, Maryland 21205, USA \\ Received: 9 May 1994 / Accepted: 21 June 1994
}

The peptidylglycine $\alpha$-amidating monooxygenase gene (PAM; EC 1.14.17.3) encodes a multifunctional protein that is composed of two enzymatic subunits, peptidylglycine $\alpha$-hydroxylating monooxygenase (PHM) and peptidyl- $\alpha$-hydroxyglycine $\alpha$-amidating lysase (PAL; Eipper et al. 1993; Ouafik et al. 1992). PHM and PAL act sequentially to catalyze the $\mathrm{COOH}$-terminal $\alpha$-amidation of many neuroendocrine peptides. The first step in generating biologically active peptides is cleavage from a larger inactive precursor protein, often generating a glycine residue at the $\mathrm{COOH}$-terminus. PHM converts the glycine residue into a peptidyl- $\alpha$-hydroxyglycine intermediate, which is subsequently converted to the $\alpha$-amidated product at physiological pH by PAL. The PHM and PAL subunits of PAM are required for the activation of all peptides bearing an $\alpha$-amide modification at their $\mathrm{COOH}$-terminus, including vasopressin, gastrin, and oxytocin. In addition, PAM transcripts have been detected in many tissues, including the heart, anterior pituitary, hypothalamus, and submaxillary gland (Ouafik et al. 1992).

The human PAM gene was assigned to $\mathrm{Chr} 5$ by analysis of somatic cell hybrids and localized on $\mathrm{Chr} 5 \mathrm{q} 14-21$ by in situ analysis (Ouafik et al. 1992, 1993). We mapped Pam to mouse Chr 1 in three individual backcrosses using RFLPs: $(\mathrm{DF} / \mathrm{B}-d f / d f \times \mathrm{CASA} / \mathrm{Rk}) \mathrm{F}_{1} \times \mathrm{DF} / \mathrm{B}-d f / d f($ Cross 1; Buckwalter et al. 1991), (C57BL/6J $\times$ M. spretus $) \mathrm{F}_{1} \times$ C57BL/6J (Cross 2; Rowe et al. 1994), and (C57BL/6J $\times$ $M$. spretus) $\mathrm{F}_{1} \times$ M. spretus (Cross 3; Rowe et al. 1994). We report the localization of Pam on mouse Chr 1 in relation to three previously reported simple sequence repeat markers: D1Mit8, D1Bir18, and D1Mit30 (Dietrich et al. 1992; Rowe et al. 1994).

The Pam gene was mapped by RFLPs with standard Southern blot procedures. Genomic DNA from crosses 1, 2, and 3 was digested with $S s p \mathrm{I}, H i n \mathrm{dIII}$, and $P s t \mathrm{I}$ respec-

Correspondence to: S.A. Camper tively. Filters were hybridized at $65^{\circ} \mathrm{C}$ with a radiolabeled 655-bp fragment of the rat PAM cDNA, rPAM-1. This portion of the cDNA is contained entirely within exon 27 and encompasses nucleotides 3231 through 3886 . Blots were washed to a final stringency of $0.1 \times$ SSC; $0.1 \%$ SDS at $57^{\circ} \mathrm{C}$. In Cross 1, D1Mit8 and DlMit30 were mapped by PCR amplification in a 96-well MJ machine under previously established conditions (Dietrich et al. 1992), except that amplified products were size fractionated on $2 \%$ agarose, $1 \%$ NuSieve (FMC Bioproducts) gels and visualized by ethidium bromide staining.

By haplotype analysis and minimization of crossover frequency, we determined the unambiguous gene order: centromere-D1Mit8-Pam-D1Bir18-D1Mit30-telomere. The distances in $\mathrm{CM}$ and estimated standard deviation between loci were: D1Mit8-7.3 $\pm 3.5-$ Pam-9.1 3.9-DlMit30 (Cross 1), DlMit8-4.6 \pm 2.6-Pam-3.2 \pm 1.8-D1Bir18 (Cross 2), and DIMit8-7.8 \pm 3.3-Pam, D1Birl8 (Cross 3).

We created a composite map of mouse Chr 1 based on these data (Fig. $1 \mathrm{C}$ ). Genes surrounding Pam on mouse Chr 1 have been assigned to human Chrs 6, 18, 2 and 1 (Fig. $1 \mathrm{~A}, \mathrm{~B}$ ). The localization of Pam to this region of mouse $\mathrm{Chr} 1$ is surprising, since all other genes on human $\mathrm{Chr} 5 \mathrm{q}$ that have previously been mapped in the mouse have been assigned to Chrs 11,13 , and 18, forming several large segments of synteny and linkage conservation. However, in all three crosses the PPAM-1 cDNA probe detected a single band on Southern blots, unambiguously demonstrating the assignment of the Pam gene, not a pseudogene, to Chr 1 (Fig. $1 \mathrm{D}$ ). Additionally, in crosses 1 and 2, a HindIII polymorphism detected with an rPAM1 cDNA probe encompassing exons 2 through 16 cosegregated with the polymorphic fragments detected with the $3^{\prime}$ UTR probe. This further confirms the localization of the Pam gene on mouse $\mathrm{Chr} 1$. The unambiguous assignment of Pam to this region of $\mathrm{Chr} 1$ displaying disrupted synteny homology suggests the introduction of a novel homology group between human $\mathrm{Chr} 5 \mathrm{q}$ and mouse $\mathrm{Chr} 1$. 


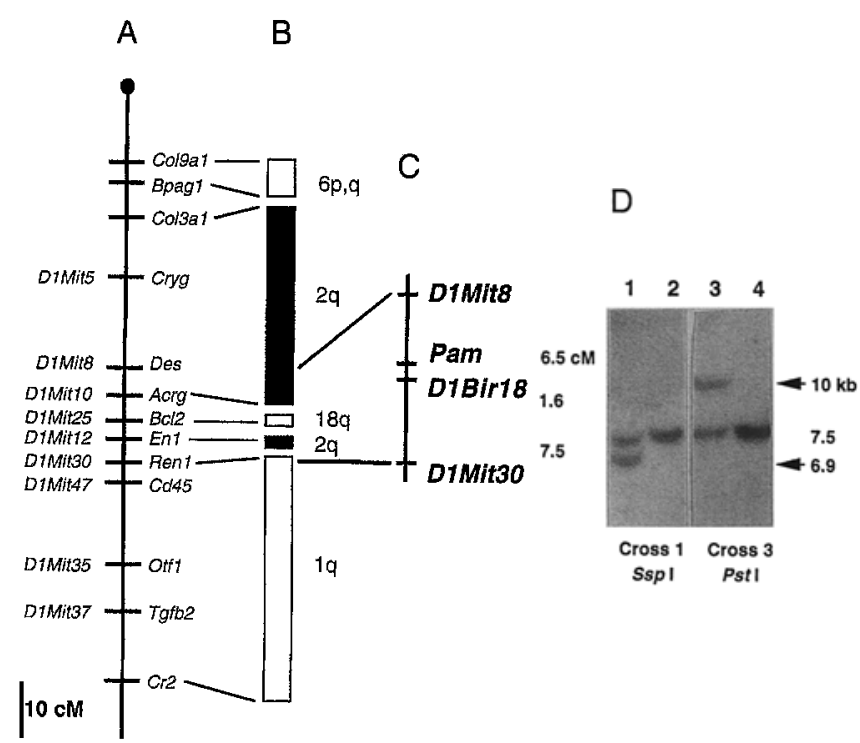

Fig. 1. Localization of Pam on mouse Chr 1. The composite map of mouse $\mathrm{Chr} 1$ shows the co-localization of simple sequence repeat markers with molecular markers (panel A; Copeland et al. 1993; Seldin et al. 1993). The human chromosomal assignment of each of the genes depicted in panel $A$ defines the regions of mouse-human synteny homology (panel B; Seldin et al. 1993). Our analysis of three backcrosses places Pam relative to DIMit8, DIBir18, and DIMit30 (panel C). The SspI RFLP revealed a CASA/Rk-specific allele of $6.9 \mathrm{~kb}$ and DF/B-df/df-specific allele of $7.5 \mathrm{~kb}$ in Cross 1 (panel D; lanes 1,2). Digestion with PstI produced a 10-kb C57BL/6 allele and 7.5-kb M. spretus allele in Cross 3 (lanes 3, 4). The arrows indicate the informative alleles present in heterozygous progeny (lanes 1,3), but absent in homozygotes (lanes 2,4).

Acknowledgments. We especially thank Lucy Rowe and The Jackson Laboratory for kindly providing Crosses 2 and 3 and for helpful discussion. We thank Marion S. Buckwalter, Ellen Lee, and The University of Michigan Reproductive Science Center Molecular Biology core (NIH
P30-GD18258) for technical assistance. This work was supported by the National Institutes of Health grants NIH R01-HD26490-010A (S.A. Camper) and NIH RO1-DK32949 (B.A. Eipper).

Data from Cross 2 and Cross 3 are deposited in MGD accession \# E1010 and \# E1035.

\section{References}

Buckwalter, M.S., Katz, R.W., Camper S.A. (1991). Localization of the panhypopituitary dwarf mutation (df) on mouse chromosome 11 in an intersubspecific backcross. Genomics 10, 515-526.

Copeland, N.G., Jenkins, N.A., Gilbert, D.J., Eppig, J.T., Maltais, L.J., Miller, J.C., Dietrich, W.F., Weaver, A., Lincoln, S.E., Steen, R.G., Stein, L.D., Nadeau, J.H., Lander, E.S. (1993). A genetic linkage map of the mouse: current applications and future prospects. Science 262 , $57-66$.

Dietrich, W., Katz, H., Lincoln, S.E., Shin, H.-S., Friedman, J., Dracopoli, N., Lander, E.S. (1992). A genetic map of the mouse suitable for typing intraspecific crosses. Genetics 131, 396-423.

Eipper, B.A., Milgram, S.L., Husten, E.J., Yun, H.Y., Mains, R.E. (1993). Peptidylglycine alpha-amidating monooxygenase: a multifunctional protein with catalytic, processing, and routing domains. Protein Sci. 2, $489-497$.

Ouafik, L., Storrers, D.A., Campbell, T.A., Johnson, R.C., Bloomquist, B.T., Mains, R.E., Eipper, B.A. (1992). The multifunctional peptidylglycine $\alpha$-amidating monooxygenase gene: exon/intron organization of catalytic, processing, and routing domains. Mol. Endocrinol. 6, $1571-1584$.

Ouafik, L., Mattei, M.G., Giraud, P., Oliver, C., Eipper, B.A., Mains, R.A. (1993). Localization of the gene encoding peptidylglycine $\alpha$-amidating monooxygenase (PAM) to human Chromosome 5q14-5q21. Genomics 18, 319-321.

Rowe, L.B., Nadeau, J.H., Turner, R., Frankel, W.N., Letts, V.A., Eppig, J.T., Ko, M.S.H., Thurston, S.J., Birdenmeier, E.H. (1994). Maps from two interspecific backeross DNA panels available as a community genetic mapping resource. Mamm. Genome 5, 253-274.

Seldin, M.F., Hunter, K., Watson, M.L. (1993). Mouse Chromosome 1. Mamm. Genome 4(Suppl.), S10-S30. 